\title{
Equilibrium and Kinetics of High Molecular Weight Protein Uptake in Ion Exchange Chromatography
}

\author{
M. Wakkel, S. Alfenore, S. Mathé, and A. Fernández
}

\begin{abstract}
Equilibrium and kinetic experiments have been carried out in order to study the effect of protein size in the purification of high molecular weight (HMW) proteins by IEC. The current work focused on two proteins uptake by $Q$ HyperZ chromatographic media. Bovine Serum Albumin (BSA) and ferritin have been selected due to their close isoelectric point (4.9 and 4.4 respectively) and their different molecular weight (66.5 and $450 \mathrm{kDa}$ respectively). As usually reported in the literature, equilibrium uptake for BSA has been higher than for ferritin at the same buffer conditions ( $\mathrm{pH}$, ionic strength), suggesting complex phenomena for ferritin uptake. Moreover, contrary to the general rule in ion-exchange processes, ferritin uptake has not been really affected by the increase of $\mathrm{NaCl}$ concentration. In fact, no significant change in the ferritin uptake has been quantified with the increasing of salt concentration from 0 to $100 \mathrm{mM}$. However, the kinetics of ferritin ion exchange has showed a classical behaviour, according to the homogenous diffusion model. The determination of the effective diffusion coefficient for ferritin has been possible from transient uptake at different protein initial concentrations. Thus, in spite of its large size, ferritin seems to diffuse inside the macro-porous anion-exchange particles.
\end{abstract}

Index Terms-Ion-exchange chromatography, isotherm, kinetic, protein purification, Q HyperZ.

\section{INTRODUCTION}

Ion-exchange chromatography (IEC) is the most extensive chromatographic technique used in separation and purification of proteins. Usually, IEC is applied with pre-purified solutions compatibles with fixed bed processes. Nevertheless, the target protein is often present in a complex feedstock with various molecules having different physico-chemical properties. The expended bed adsorption (EBA) has been developed as an efficient technique for the recovery of proteins directly from complex feedstock which the target protein is competitively adsorbed by the ion exchanger. A recent study at laboratory scale has shown that EBA can give high production yield and high purity for a HMW protein (RubisCo, $560 \mathrm{kDa}$ ) from crude and complex medium in spite of the presence of many other species with different molecular weight and isoelectric point [1]. For these systems, studying the effect of protein's molecular weight on adsorption system could be a very important issue that deserves special attention.

Both the equilibrium uptake capacity and the mass transfer rate affect the performance of ion exchangers. Thus,

Manuscript received December 5, 2014; revised January 29, 2015. This work is supported by the French Ministry of Higher Education and Research.

The authors are with the Institut National des Sciences Appliquées, Toulouse, France (e-mail: wakkel@insa-toulouse.fr, alfenore@insatoulouse.fr, mathes@insa-toulouse.fr,mafernan@insa-toulouse.fr). understanding how they are influenced by protein size in IEC system is necessary. Adsorption isotherms describe the equilibrium distribution of a solute between the two phases involved in the chromatographic process (mobile and stationary) over a wide concentration range. This gave information about the solute, the adsorbent, and their interaction levels. The molecular weight affects not only the saturation capacity but also the effective diffusivity of the species which is related to the accessible porosity and tortuosity of the ion exchanger. In fact, the step that usually limits the rate of transfer is the intra-particle diffusion, especially for macromolecules such as proteins [2]. So the study of intra-particle transport is a valuable route for achieving systematic design of chromatographic operations.

Only few authors have reported the adsorption behaviour for a range of differently sized proteins under strong binding conditions [3]-[6]. Gu et al. [3] suggested that the component of larger molecular size tended to have a smaller saturation capacity because it has few chances to penetrate inside the particles since some binding sites on the surfaces of macro-pores can be blocked due to size exclusion. So, the least excluded component tended to have the highest saturation capacity and vice versa. Johnston and Hearn [4] investigated the adsorption of human serum albumin, carbonic anhydrase, and ferritin by various macro-porous weak anion exchangers. Their findings suggest that the effective pore diffusivity of the smaller proteins are closed to the free solution diffusivities, indicating a negligible restriction to mass transfer through the pores. However, the effective pore diffusivity of ferritin has been found to be only $1 / 40$ of the one in free solution, consistent with severely hindered diffusion and highlighting the influence of protein size on pore accessibility. Hunter and Carta [6] considered that electrostatic interactions allow to overcome size exclusion limitation for proteins. Ferritin, which is the largest protein studied, appeared as the limiting case.

Ionic strength is also recognized as one of the most important factors affecting the equilibrium of the proteins ion exchange [7]. So it is often used in order to understand ion exchange systems. In a preparative IEC system, protein uptake depends on both protein-protein and protein-surface interactions, which are affected by ionic strength. The latter was extensively discussed and considered as the dominant factor in ion-exchange adsorption of proteins (as for BSA).

The anion exchanger Q HyperZ used in this work is known by its high protein adsorption capacity and its application domain in EBA. This chromatographic matrix is constituted of small and highly dense particles [8]. The pores of these particles are filled with a high charge-density hydrogel. Few previous studies investigated protein equilibrium and mass transfer in this composite ion-exchanger. Fernandez and 
Carta [5] studied the batch uptake of $\alpha$-lactalbumin, ovalbumin, and BSA on Q-HyperD resin which had the same filled poly-acrylamide gel but differed by the rigid matrix (Silica matrix). Lewus and Carta [9] investigated the uptake of lysozyme and cytochrome-c on S-HyperD-M. Hunter and Carta [6] used the anion exchanger BRX-Q and reported that some characteristics of the Q-HyperD resin, namely high capacity and rapid diffusion, were similar. All these papers focused on adsorption systems with proteins smaller than ferritin.

The aim of this work is to investigate the influence of the molecular weight of proteins on the equilibrium and the kinetic behaviour in IEC system. Bovine Serum Albumine (BSA) and ferritin have been chosen as model proteins for low and high molecular weight. They have been selected for their similar Ip and their different molecular weights (i.e. 66.5 and $450 \mathrm{kDa}$ for BSA and ferritin respectively [6]). Uptake equilibrium and intra-particle mass transfer models were used to describe experimental data obtained from independent batch experiments.

\section{THEORY}

\section{A. Uptake Equilibrium}

Uptake isotherms became a major tool for the investigation of the phenomena involved in chromatographic processes. The functional relationship describing the distribution of solutes between the sorbent and the bulk solution at equilibrium and at constant temperature is called equilibrium isotherm.

Over the past decades, various adsorption models are reported to describe the ion-exchange equilibrium of proteins [10]-[13]. In all those studies, the most frequently used ones was the Langmuir model and its various modified forms [14], [15]. The Langmuir model assumes that (i) all binding sites are equivalent and independent; (ii) each binding site adsorbs just one solute; (iii) a molecule adsorbed onto one binding site does not influence the adsorption of another molecule on a neighbouring binding site without interaction among adsorbed species and (iv) the molecules form only a single monolayer [16]. For a mono-component adsorption system, Langmuir model is based on the following equation:

$$
q=\frac{Q \cdot K_{L} \cdot C}{1+K_{L} \cdot C}
$$

where $q$ and $C$ are the equilibrium concentrations of the solute in solid and liquid phases respectively, $Q$ represents the maximum binding capacity and $K_{L}$ is the affinity or dissociation coefficient of the solute-adsorbent complex, which describes the affinity of the system [17]. Linearizing (1) allows to obtain $Q$ and $K_{L}$ parameters from the slope and the intercept.

The Langmuir isotherm is widely accepted as a useful method for fitting experimental data of protein adsorption into ion exchange/affinity adsorbents. However, in the case of protein ion exchange, some of the above assumptions are not completely realistic turning the Langmuir model as an empirical mathematical model more than a rigorous theoretical one. Moreover, it was reported by many authors [18], [13], [19] that Langmuir model can be used to describe adsorption isotherms at constant $\mathrm{pH}$ and ionic strength.

\section{B. Kinetics of IEC System}

In addition to uptake capacity, mass transfer rates are also critically important for assessing the performance of ion-exchange media. External film resistance and intra-particle mass transfer resistance (Fig. 1) can affect ion-exchange kinetics in a gel-type chromatographic resin [5]. In order to fully understand and to predict the performances of the purification process, detailed knowledge of the adsorption kinetics and the diffusive behaviour are required. A number of studies were devoted to protein mass transfer in chromatographic media [20]-[23]. Modelling the mass transfer has been extensively developed in the last three decades and many articles have been published on this subject.

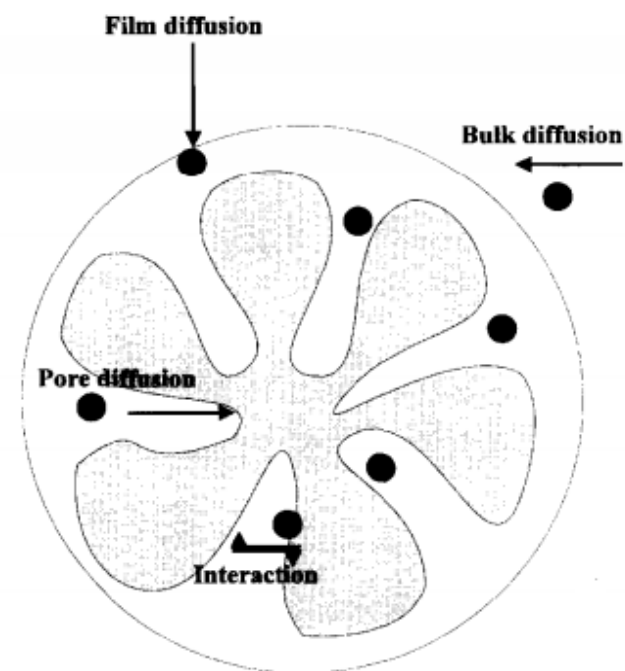

Fig. 1. Schematic representation of the mass transfer of a protein molecule into porous adsorbent particle [24].

In those studies, many models have been discussed to account for the intra-particle mass transport inside the adsorbent particles. Basically, four models have been used: homogenous diffusion model [25]; pore diffusion model [26], [25]; surface diffusion model [27] and parallel diffusion model [20], [28], and [29]. All these models are based on the following assumptions [20], [26], [27]:

1) The adsorbent particles are spherical and uniform in size and density. The functional groups of the ion exchanger are evenly distributed throughout the interior surface of the particle.

2) The liquid film mass transfer resistance can be neglected

3) Protein concentration in the pores is in local equilibrium with the concentration of protein adsorbed on the inner surface of the pore wall.

In the homogeneous diffusion model (used in this work), the adsorbent particle is considered as a homogeneous network, and the driving force for protein diffusion is the total protein concentration gradient in the adsorbent [25]. The continuity equation for the intra-particle mass transfer by homogeneous diffusion is written as:

$$
\frac{\partial \dot{q}}{\partial t}=\frac{D_{e}}{r^{2}} \cdot \frac{\partial}{\partial r} \cdot\left(r^{2} \cdot \frac{\partial \dot{q}}{\partial r}\right)
$$

where $D_{\mathrm{e}}$ represents the effective diffusivity and $\dot{q}$ is the 
local protein uptake. The mass transfer of protein from liquid phase to the solid phase is expressed by:

$$
\frac{\partial C}{\partial t}=-\frac{3 V_{R} D_{e}}{V_{L} R_{p}}\left(\frac{\partial \dot{q}}{\partial r}\right)_{r=R_{p}}
$$

where $V_{R}$ is the volume of resin, $V_{L}$ is the volume of solution, and $R_{p}$ is the mean particle radius.

The initial (IC) and boundary (BC) conditions for this model are:

$$
I C: t=0, q=0, C=C_{0}
$$

where $C_{0}$ is the initial protein concentration and $q$ the average protein concentration in the resin.

$$
\begin{gathered}
B C(1): r=R_{p} \quad D_{e} \frac{\partial \dot{q}}{\partial r}=K_{f}\left(C-C_{i}\right) \\
B C(2): r=0, \frac{\partial \dot{q}}{\partial r}=0
\end{gathered}
$$

where $K_{f}$ is the film mass transfer coefficient.

Under intra-particle mass transfer control, $\dot{q}_{i}=\dot{q}_{R_{p}}=\dot{q}_{0}$, and (2) can be integrated directly yielding the well known result [30]:

$$
\frac{q}{Q}=1-\frac{6}{\Pi^{2}} \sum_{k=1}^{\infty} \frac{1}{K^{2}} \exp \left(-\frac{K^{2} \cdot \Pi^{2} \cdot D_{e}}{R_{p}{ }^{2}} \cdot t\right)
$$

A useful approximation of this series solution suitable for approximate numerical calculations has been given by Helfferich and Plesset [31] as:

$$
\frac{q}{Q}=\left[1-\exp \left(\Pi^{2}\left(-\tau+0,960 \cdot \tau^{2}-2,92 \cdot \tau^{3}\right)\right)\right]^{1 / 2}
$$

where

$$
\tau=\frac{D_{e} . t}{R_{p}^{2}}
$$

Under external film mass transfer control, $C_{i} \sim 0$. Thus (3) can be integrated directly yielding the following result for the protein concentration in solution, $C$, and for the average protein concentration in the adsorbent $q$ :

$$
\begin{gathered}
\frac{C}{C_{0}}=\exp \left(-\frac{3 \cdot K_{f} \cdot V_{R}}{R_{p} \cdot V_{L}}\right) \cdot t \\
q=\frac{V_{L} \cdot C_{0}}{V_{R}}\left(1-\exp \left(-\frac{3 K_{f} \cdot V_{R}}{R_{p} \cdot V_{L}} \cdot t\right)\right)
\end{gathered}
$$

The relative importance of external and intra-particle mass transfer resistances is strongly dependent on the experimental conditions.

\section{MATERIAL AND METHODS}

\section{A. Chromatographic Media}

The Q HyperZ anion exchanger consists in small and dense particles with a porous core made from zirconium oxide [9]. The pores are filled with a high charge-density hydrogel containing quaternary ammonium groups and are synthesized through polymerization of methacryloyl-aminopropyl -trimethylammonium with the crosslinker $N, N_{-}$-methyl-bismethacrylamide [32]. The term "gel-in-a-shell" was applied to adsorbents in which the whole pore space was occupied by a cross-linked gel structure. The name of HyperZ reflected the rapid "Hyper-diffusive" transport observed during protein uptake. Q HyperZ adsorbents with lot numbers 210120/C105, were received as gifts from Pall Corporation (BioSepra, Ciphergen, France). The size distribution of chromatographic matrix was $40-105 \mu \mathrm{m}$ with an average of $75 \mu \mathrm{m}$ according to the manufacturer.

\section{B. Proteins}

Two different proteins were used as model species: BSA (MW-66.5kDa, Ip-4.9) and ferritin (MW- $450 \mathrm{kDa}, \mathrm{Ip}-4.4)$. BSA and ferritin were of analytical-grade and purchased from Sigma Aldrich. Proteins were used as received from the vendor without further purification. Protein solutions were prepared by dissolving these samples in $50 \mathrm{mM}$ Tris-HC1 aqueous buffers at $\mathrm{pH}$ 8.5. At this $\mathrm{pH}$, each protein is strongly negatively charged which was suitable for ion-exchange with the strong anion exchanger Q HyperZ. BSA and ferritin solution concentrations were measured by Jasco Spectrophotometer (Model V-630, France) after the establishment of the appropriated calibration curves. Protein concentrations were determined from the absorbance at 280 $\mathrm{nm}$ using a 2-mL quartz cuvette. All aqueous solutions were prepared using purified (Milli-Q) water prepared in the laboratory.

\section{Uptake Equilibrium}

Uptake equilibrium experiments of BSA and ferritin on the anion exchanger were performed in batch contactor in Tris- $\mathrm{HCl}$ buffer $(50 \mathrm{mM}, \mathrm{pH} 8.5)$ at $25^{\circ} \mathrm{C}$.

A known amount ( $0.34 \mathrm{~g}$ wet resin) of the anion exchanger pre-equilibrated in the buffer was added to each flask containing a known volume $(9 \mathrm{ml})$ of buffered protein at different solution concentrations ranged from $0.25 \mathrm{~g} / \mathrm{L}$ to 4 $\mathrm{g} / \mathrm{L}$. Experiments were carried out at three salt concentrations ( $0 \mathrm{mM}, 50 \mathrm{mM}$ and $100 \mathrm{mM} \mathrm{NaCl})$. The same conditions were used for both proteins.

The flasks were shaken for $1.5 \mathrm{~h}$ and $5 \mathrm{~h}$ for BSA and ferritin respectively on a shaking incubator (70 rpm). The ion exchanger was settled and the supernatant was filtered before determining the equilibrium protein concentration with spectrophotometer at $280 \mathrm{~nm}$. The amount of protein adsorbed to HyperZ anion exchanger was then calculated by the following material balance:

$$
q=\frac{V_{L}\left(C-C_{0}\right)}{V_{R}}
$$

where $q$ was the amount of protein adsorbed $(\mathrm{g} / \mathrm{L}), V_{L}$ was the volume of solution (L), $V_{R}$ was the volume of media $(\mathrm{L}), C_{0}$ and $C$ were respectively the initial and equilibrium protein concentrations $(\mathrm{g} / \mathrm{L})$ in solution.

Since the total water content of the media samples used varied slightly from run to run, results were expressed in terms of the volume of dry particles. In order to obtain this volume, the moisture content determined by drying at $120^{\circ} \mathrm{C}$ $(\sim 25 \%)$ and the known density of the dry medium $(3.2 \mathrm{~g} / \mathrm{mL})$ were used.

It should be noticed that in the experimental data, the salt 
concentration referred to $\mathrm{NaCl}$ added to the solution. The final ionic strength depended on both the sodium chloride coming from the Tris- $\mathrm{HCl}$ buffer and a part of salts stabilizing the protein stock solution that was neglected $(\sim 3$ $\mathrm{mM})$.

\section{Kinetic Study}

Adsorption kinetics of BSA and ferritin in the anion exchanger were performed in the Tris- $\mathrm{HCl}$ buffer $50 \mathrm{mM}(\mathrm{pH}$ 8.5, $0 \mathrm{mM} \mathrm{NaCl}$ ). Flasks containing $9 \mathrm{ml}$ of buffered protein solutions at the same initial concentration $(3 \mathrm{~g} / \mathrm{L})$ were pre-incubated in the shaking incubator at $25^{\circ} \mathrm{C}$. This high concentration was selected to overcome the film mass transfer resistance as mentioned in the work of Fernandez and Carta [5]. The rigorously same amount of the anion exchanger pre-equilibrated in the buffer was added to each flask. The mixture in the flasks was suspended in the incubator shaking at $70 \mathrm{rpm}$ for a well-known time depending on protein. For each time, supernatant was taken out from the incubator and filtered $(2 \mu \mathrm{m}$ stainless filter) before protein concentration measurements. In order to investigate the effect of initial concentration in ferritin uptake kinetics, experiments were also carried out at 0.1 and $1.7 \mathrm{~g}$ ferritin/L besides to $3 \mathrm{~g} / \mathrm{L}$ highlighted previously.

\section{RESUlTS AND DisCUSSION}

\section{A. Uptake Equilibrium}

The results of BSA and ferritin uptakes by Q HyperZ are represented in Fig. 2 which shows the protein concentration in the resin as a function of the protein concentration in the solution at the equilibrium. The uptake equilibrium of BSA shows a highly non-linear favourable shape contrarily to the ferritin isotherm which is less steep, as reported in the literature for similar chromatographic media [5], [6]. Moreover, BSA uptake capacity (212 g/L) was significantly higher than ferritin $(52.1 \mathrm{~g} / \mathrm{L})$ under the same buffer conditions (50 mM Tris- $\mathrm{HCl}, \mathrm{pH} 8.5$ ).

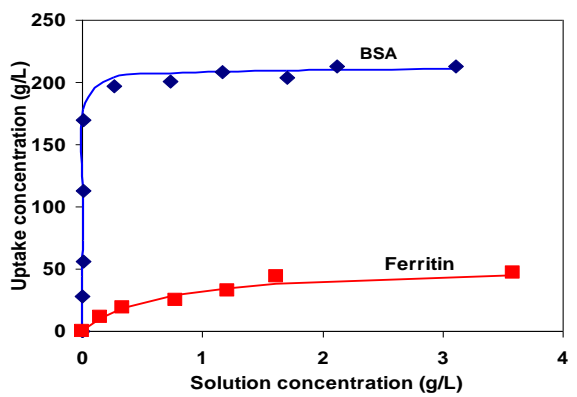

Fig. 2. Equilibrium uptake of BSA and ferritin by QHyperZ in a $50 \mathrm{mM}$ Tris-HC1 buffer at $\mathrm{pH}$ 8.5. Symbols represent experimental data and solid lines represent theoretical results given by Langmuir isotherm.

The Langmuir isotherm was used in this work for fitting experimental results. Even when the Langmuir model does not impose constraints of ion-exchange theory (such as the electro-neutrality of the system), it is usually used to fit equilibrium results due to its simplicity and its good agreement with experimental data [7]. Langmuir parameters can be determined by linearizing (1) as represented in (13) [33]:

$$
\frac{C}{q}=\frac{1}{Q \cdot K_{L}}+\frac{C}{Q}
$$

For experimental conditions far from the equilibrium, a plot of $C / q$ versus $C$ allows easily to determine $Q$ and $K_{L}$. For both proteins, Langmuir parameters are summarized in Table I. The theoretical equilibrium uptake is represented in Fig. 2 for both proteins.

These results agree well with the work of Hunter and Carta [6] who studied the effect of proteins molecular weight on the adsorption capacity by BRX-Q anion exchanger, as it has been mentioned in the introduction.

TABLE I: LANGMUIR PARAMETERS FOR BSA AND FERRITIN UPTAKE BY Q HYPERZ MEDIA IN A 50MM TRIS-HCI BUFFER AT PH 8.5

\begin{tabular}{lll}
\hline \hline & BSA & Ferritin \\
\hline$Q(\mathrm{~g} / \mathrm{L})$ & 212.0 & 52.1 \\
$K_{L}(\mathrm{~L} / \mathrm{g})$ & 52.0 & 1.6 \\
\hline \hline
\end{tabular}

In their work, the uptake has been founded $280 \mathrm{~g} / \mathrm{L}$ for BSA and $50 \mathrm{~g} / \mathrm{L}$ for ferritin (prepared on the same buffer conditions, Tris $\mathrm{HCl}-50 \mathrm{mM}, \mathrm{pH} 8.5$ ). Ferritin uptake was found very low presumably because of its large size and the hindrance caused by the physical properties of the adsorbent particles (tortuosity, porosity). Indeed Hunter and Carta [6] indicated that, under binding conditions, the favourable electrostatic interaction between the stationary phase and the protein has to overcome the unfavourable size exclusion phenomenon. For larger proteins, the barrier imposed by size may be great to overcome. That was apparently the case for ferritin. This can be corroborated by the measurements carried out by dynamic light scattering which showed the difference between the hydrodynamic diameter of BSA (8.0 $\mathrm{nm})$ and ferritin $(15.1 \mathrm{~nm})$ (data not shown).

Anyway, in order to better understand the behaviour of ferritin inside the adsorbent, we also investigated the effect of salinity on equilibrium uptake, as a key variable for the analysis of ion-exchange mechanisms. As usually, BSA was also studied as a reference.

\section{1) Low molecular weight protein: BSA case}

Fig. 3 shows experimental and theoretical results (Langmuir equation) of BSA uptake equilibrium by $\mathrm{Q}$ HyperZ for three $\mathrm{NaCl}$ solution concentrations. For each salt concentration, the maximum uptake capacity $(Q)$ and the affinity parameter $\left(K_{L}\right)$ were determined and the results are summarized in Table II. As expected, BSA uptake strongly decreased and the isotherm became less favourable as the salt concentration increased.

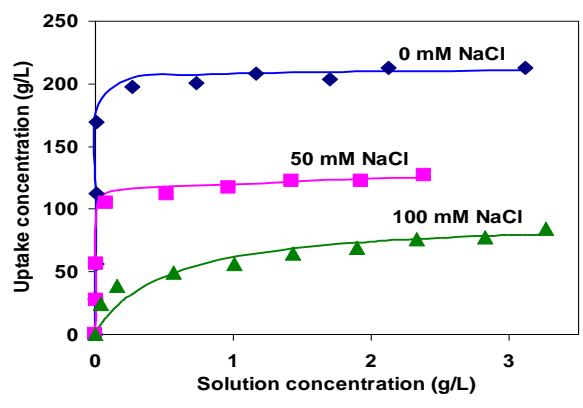

Fig. 3. Equilibrium uptake of BSA by QHyperZ in a $50 \mathrm{mM}$ Tris-HC1 buffer at $\mathrm{pH} 8.5$ for different salt concentrations.Symbols represent experimental data and solid lines represent theoretical results given by Langmuir isotherm. 
Indeed, as the salt concentration increased, significantly lower $Q$ values were found: $126.6 \mathrm{~g} \mathrm{BSA} / \mathrm{L}$ for $50 \mathrm{mM} \mathrm{NaCl}$ and $92 \mathrm{~g} \mathrm{BSA} / \mathrm{L}$ for $100 \mathrm{Mm} \mathrm{NaCl}$ compared to $212 \mathrm{~g} \mathrm{BSA} / \mathrm{L}$ at $0 \mathrm{mM} \mathrm{NaCl}$ concentration (Table II). In the same way, $K_{L}$ values calculated for BSA uptake by Q HyperZ decreased significantly with salt concentration showing less affinity and weaker binding strength of BSA on adsorbent particles (Table II).

TABLE II: LANGMUIR PARAMETERS FOR BSA UPTAKE BY Q HYPERZ MEDIA IN A 50MMTRIS-HCI BUFFER AT PH 8.5

\begin{tabular}{llll}
\hline \hline & $0 \mathrm{mMNaCl}$ & $50 \mathrm{mMNaCl}$ & $100 \mathrm{mMNaCl}$ \\
\hline$Q(\mathrm{~g} / \mathrm{L})$ & $212.0 \pm 7.8$ & $126.6 \pm 3.5$ & $92 \pm 2.9$ \\
$K_{L}(\mathrm{~L} / \mathrm{g})$ & 52.0 & 26.3 & 2.0 \\
\hline \hline
\end{tabular}

All these results agree with the work of Fernandez and Carta [5] carried out with a similar anion exchanger (Q HyperD filled with the same hydrogel).

\section{2) High molecular weight: Ferritin case}

The ferritin uptake curves are shown in Fig. 4 as the protein concentration in the resin as a function of the protein concentration in the solution for the three salt concentrations $(0,50$ and $100 \mathrm{mM})$. Experimental and theoretical results from Langmuir equation are represented.

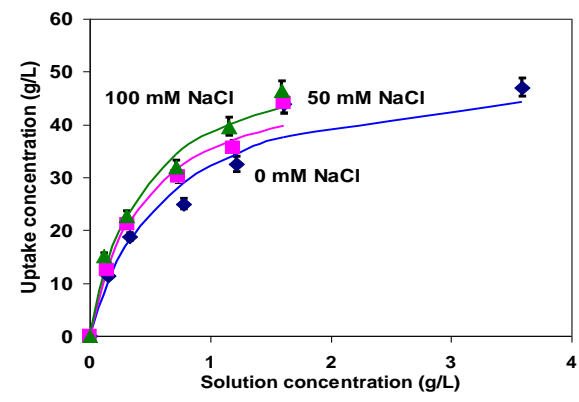

Fig. 4. Equilibrium uptake of ferritin by Q-HyperZ media in a $50 \mathrm{mM}$ Tris-HC1 buffer at $\mathrm{pH} 8.5$ for different salt concentrations. Symbols represent experimental data and solid lines represent theoretical results given by Langmuir isotherm.

As seen in Fig. 4, the presence of salt does not appear to alter significantly the ferritin uptake within this range of ionic strength. In fact, no significant change was observed for ferritin uptake by Q HyperZ for both the maximal adsorption capacity $(Q)$ and the protein affinity $\left(K_{L}\right)$.

TABLE III: LANGMUIR PARAMETERS FOR FERRITIN UPTAKE BY Q HYPERZ MEDIA IN A 50 MM TRIS-HCI BUFFER AT PH 8.5 FOR DIFFERENT SALT CONCENTRATIONS

\begin{tabular}{llll}
\hline \hline & $0 \mathrm{mMNaCl}$ & $50 \mathrm{mMNaCl}$ & $100 \mathrm{mMNaCl}$ \\
\hline$Q(\mathrm{~g} / \mathrm{L})$ & $52,1 \pm 1.7$ & $50.5 \pm 1.7$ & $55.0 \pm 1.8$ \\
$K_{L}(\mathrm{~L} / \mathrm{g})$ & 1.6 & 2.3 & 2.3 \\
\hline \hline
\end{tabular}

Generally, salts are considered to have an effect on the protein properties (i.e. salt can stabilized protein charges), on the ion-exchange particles (i.e. salt ions can be fixed by ion exchanger) and on the interactions between protein and chromatographic media.

Huang et al. [34] highlighted that the adsorption of macromolecules was a multipoint system as represented by Andreas et al. [35] in Fig. 5.
Thus, for large proteins such as ferritin, it can be considered that the addition of salts does not decrease significantly the interactions between protein and adsorbent since its adsorption takes place simultaneously in many resin sites.

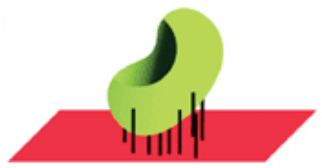

Fig. 5. Protein multipoint adsorption [35]

In fact, the increasing of the salt concentration could shield some charges of the ferritin or modified some interactions between ferritin and the resin but globally the system keeps the same adsorption capacity and almost the same affinity for Q HyperZ in the range of the studied salt concentrations.

\section{3) Comparison of BSA and ferritin}

BSA and ferritin behaviours have been compared upon the adding of different salt concentrations ranged from 0 to 100 $\mathrm{mM} \mathrm{NaCl}$. In Fig. 6, maximum adsorption capacity $(Q)$ Fig. 6(a) and dissociation coefficient $\left(K_{L}\right)$ Fig. 6(b) are represented as a function of $\mathrm{NaCl}$ concentration for both proteins showing clear differences between BSA and ferritin.
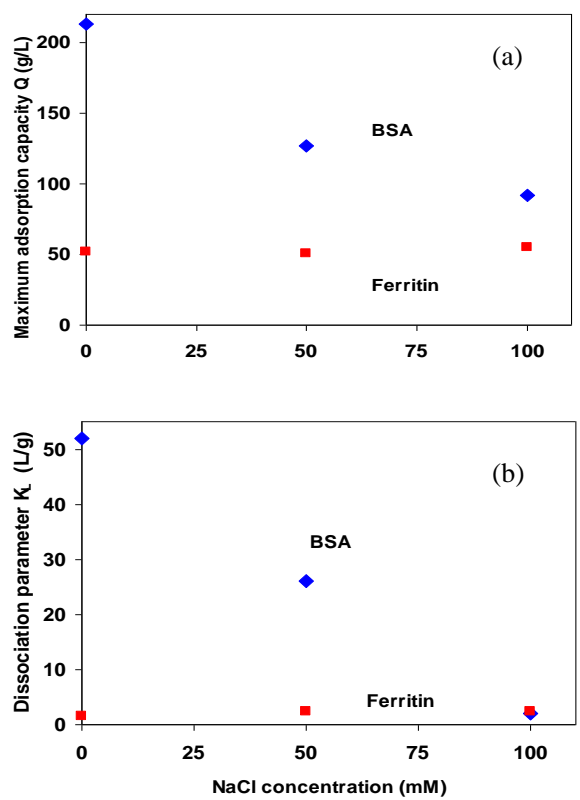

Fig. 6. Effect of salt concentration on the maximum adsorption capacity, $Q$ (a) and the affinity coefficient, $K_{L}$ (b) for BSA and ferritin on Q Hyper Z adsorbent at $25^{\circ} \mathrm{C}$ (Tris- $\mathrm{HCl}$ buffer $50 \mathrm{mM}, \mathrm{pH} 8.5$ ).

The significant decrease of the binding capacity $(Q)$ and affinity $\left(K_{L}\right)$ for BSA resulting from the increase of ionic strength are generally attributed to the interactions between salt ions and protein molecules and between salt ions and adsorbents, as mentioned before. Those effects influence electrostatic and Van Der Waals interactions between the protein molecules and the ion-exchange resin [7].

Contrarily to BSA, as salt concentration increased from 0 to $100 \mathrm{mM}$, adsorption capacity for ferritin did not drop obviously. This result for ferritin was not yet reported in the literature and can illustrate specific phenomena for salt effect in ion exchange of large proteins. As previously outlined, Velayudhan [36] suggested that bound macromolecules, by virtue of their size, would be expected to cover significantly 
more sites than dictated by their characteristic charge (multipoint adsorption) and to induce high steric hindrance. In the range of salt concentrations studied, the addition of salt does not influence significantly the uptake capacity of ferritin, which is a very large protein. This shows that multipoint adsorption plays probably an important role in their uptake.

Moreover, the functional groups of anion exchanger can be shielded by the ferritin steric hindrance but the presence of salt does not avoid ferritin uptake. Thus, no significant changes take place in ferritin uptake with salt addition due to ferritin multipoint adsorption and steric hindrance. Kerfai [1] studied the RubisCo (MW $560 \mathrm{kDa}$ ) uptake by Q HyperZ from crude feedstock in expanded bed adsorption. It was reported that Rubisco uptake does not decrease obviously with the increase of solution ionic strength.

\section{B. Kinetic Study}

Experimental results of BSA and ferritin uptake kinetics by Q HyperZ are represented (symbols) in Fig. 7 as the amount of protein taken up as a function of time. For all experiments, the limitation by external mass transfer (determined by representing $\ln C / C_{0}$ as a function of $t$, according with (10) was negligible (data not showed). Fig. 7 shows that the uptake rate is slower for ferritin than for BSA due to its lower free aqueous solution diffusivity $\left(D_{0}\right)$ (Table IV). Q HyperZ saturation was reached after 20 min for BSA and after $250 \mathrm{~min}$ for ferritin.
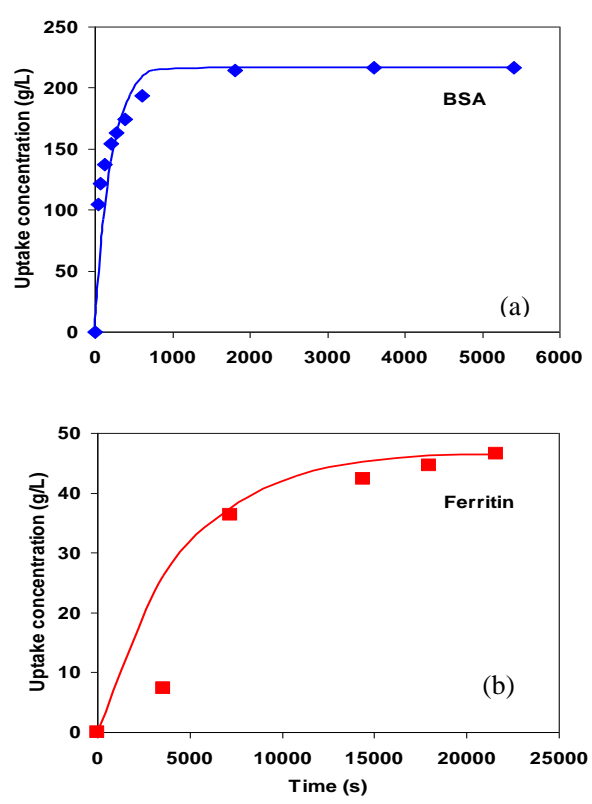

Fig. 7. Kinetic uptake curves for BSA (a) and ferritin (b) (Tris-HCl buffer $50 \mathrm{mM}, \mathrm{pH}$ 8.5). Symbols represent experimental results. Solid lines represent theoretical results calculated by using the homogeneous diffusion model with parameters in Table IV.

According to Fernandez and Carta [5], homogenous diffusion model has been used in this work to analyse the experimental data. This model assumed that the intra-particle mass transfer is proportional to the adsorbed protein concentration gradient in the anion-exchange particles. For each protein, $D_{e}$ was determined by fitting (9) to experimental data. The theoretical values of transient uptake are represented in Fig. 7 (solid lines), and the resulting values of $D_{e}$ are summarized in Table IV.

As expected, the $D_{e}$ values decrease dramatically with the protein size (10 times). Some experimental values of $D_{e}$ have been reported in the literature for macromolecules in porous materials. Hunter and Carta [6] studied the adsorption kinetics of proteins (ovalbumin, BSA, conalbumin) with different molecular weights on BRX-Q anion exchanger.

TABLE IV: KINETIC PARAMETERS OBTAINED FROM THE HOMOGENEOUS DIFFUSION MODEL FOR BSA AND FERRITIN UPTAKE BY Q HYPERZIN 50 MM TRIS-HCL BUFFER

\begin{tabular}{llll}
\hline \hline & $D_{0}{ }^{a}\left(\mathrm{~cm}^{2} / \mathrm{s}\right)$ & $D_{e}\left(\mathrm{~cm}^{2} / \mathrm{s}\right)$ & $D_{e} / D_{0}$ \\
\hline BSA & $610^{-7}$ & $7.510^{-9}$ & 0.013 \\
Ferritin & $3.610^{-7}$ & $3.510^{-10}$ & 0.001 \\
\hline \hline
\end{tabular}

$a:[6]$

They reported that for initial concentration of $2 \mathrm{~g} / \mathrm{L}$, the diffusion coefficient of ovalbumin $(45 \mathrm{kDa})$ and BSA (66 $\mathrm{kDa}$ ) were $7.710^{-9}$ and $2.410^{-9} \mathrm{~cm}^{2} / \mathrm{s}$ respectively. Fernandez and Carta [5] reported $9.210^{-9} \mathrm{~cm}^{2} / \mathrm{s}$ as the intra-particle diffusivity of BSA into composite silica-polyacrylamide gel anion exchanger (Q HyperD). Kerfai [1] has investigated the intra-particle diffusion of RubisCo (560 kDa) in Q HyperZ and has showed that the effective diffusion coefficient was 5 $10^{-10} \mathrm{~cm}^{2} / \mathrm{s}$ which is comparable to the value obtained in this study for ferritin. From these results, it cannot be concluded that size exclusion prevent the ferritin uptake by Q HyperZ.

Moreover, transient ferritin uptake was studied at different initial concentration of ferritin in the solution and the homogeneous diffusion model was applied to experimental results. Fig. 8 shows the experimental (symbols) and theoretical (solid lines) results as transient ferritin uptake as a function of time. As seen in Fig. 8, the same effective diffusivity $\left(D_{e}=3.510^{-10} \mathrm{~cm}^{2} / \mathrm{s}\right)$ value provided an excellent fit of the ferritin uptake for all the initial protein concentrations studied $(0.1,1.7$ and $3 \mathrm{~g} / \mathrm{L})$.

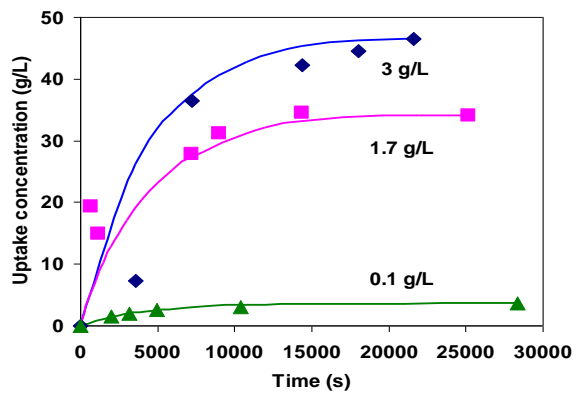

Fig. 8. Ferritin kinetic uptake curves for different initial concentration (Tris- $\mathrm{HCl}$ buffer $50 \mathrm{mM}$, pH 8.5). Solid lines represent theoretical results calculated by using the homogeneous diffusion model with parameters in Table IV.

Hunter and Carta [6] determined $D_{e} / D_{0}$ ratio for BSA in BRX-Q adsorbent to be equal to 0.004 which is 3.25 times less than $D_{e} / D_{0}$ ratio for BSA in Q HyperZ in spite of the same hydrogel and buffer conditions $(50 \mathrm{mM}$ TrisHCl, $\mathrm{pH}$ 8.5). In fact, this difference is probably related to the physical properties of the ion exchanger which cause different restriction behaviours.

In this context, Frey et al. [37] introduced a correlation between the effective diffusivity $\left(D_{e}\right)$ and the free aqueous solution diffusivity $\left(D_{0}\right)$ as it is indicated in the following equation:

$$
D_{e}=\frac{\varepsilon_{p} \cdot D_{0}}{\tau} \lambda
$$

where $\varepsilon_{p}$ is the particle porosity, $\tau$ is the particle tortuosity and $\lambda$ 
is the steric hindrance factor. For a chromatographic medium, the ratio $\varepsilon_{\mathrm{p}} / \tau$ is constant. As indicated in the Table IV, the $D_{e} / D_{0}$ ratio is very low for both studied proteins indicating a high diffusional hindrance $(\lambda)$ under these conditions. In fact, this ratio is about 0.001 for ferritin suggesting that this protein encounters more diffusional hindrance in comparison with BSA (0.013). This result agrees well with the uptake equilibrium experiments.

\section{CONCLUSION}

The equilibrium and kinetic uptake of two proteins with different size and similar isoeletric-point have been studied in the composite anion exchanger Q HyperZ. BSA has been used as model protein and ferritin was representative for high molecular weight protein. BSA uptake capacity has been determined to be almost 5 times more than ferritin uptake. Moreover, the salt effect in both systems has been investigated in order to better understand the uptake mechanisms of HMW protein. As expected, the uptake capacity for BSA decreased as the salt concentration increased since the functional groups of the media and/or the charges of protein have been shielded by the ions from the salt. However, an exceptional behaviour has been relieved for ferritin because any significant change of the maximum uptake capacity has been highlighted in the range of salt concentrations studied $(0,50$ and $100 \mathrm{mM} \mathrm{NaCl})$. For ferritin, other possible mechanisms such as multipoint adsorption and steric hindrance have been suggested. Homogenous diffusion model has been used in order to represent transient uptake and to determine effective diffusion values for ferritin. For the different protein concentrations, the model agreed well with experimental data suggesting the penetration of ferritin inside particles. $D_{e}$ values when compared with $D_{0}$ for BSA and ferritin allowed the determination of the steric hindrance factor for ferritin which is much more important than for BSA.

\section{ACKNOWLEDGMENT}

The authors want to thank PALL BioSepra for the kind gift of Q HyperZ adsorbents.

This work was supported by the French Ministry of Higher Education and Research. We are grateful for its financial support.

\section{REFERENCES}

[1] S. Kerfai, "Etude d'un procédéchromatographiqued'échanged'ions pour la separation de la Ribulose 1,5-Biphosphate Carboxylase Oxygénase (RuBisCO) dans le cadre de la valorisation d'un sous produitagricole," PhD Thesis Toulouse University, France, 2011.

[2] Y. Sun and K. Yang, "Analysis of mass transport models based on Maxwell-Stefan Theory and Fick's law for protein uptake to porous anion exchanger," Separation and Purification Technology, vol. 60, pp 180-189, 2008.

[3] T. Gu, G. J. Tsai, and G. T. Tsao, "Multicomponent adsorption and chromatography with uneven saturation capacities," AIChE Journal, vol. 37, no. 9, pp. 1333-1340, September 1991.

[4] A. Johnston and M. T. W. Hearn, Journal of Chromatography, vol. 557, pp. 335, 1991.

[5] M. A. Fernandez and G. Carta, "Characterization of protein adsorption by composite silica-polyacrylamide gel anion exchangers-Part I: Equilibrium and mass transfer in agitated contactors," Journal of Chromatography A, vol. 746, pp. 169-183, April 1996.

[6] A. K. Hunter and G. Carta, "Protein adsorption on novel acrylamido-based polymeric ion-exchangers —Part IV: Effects of protein size on adsorption capacity and rate," Journal of Chromatography A, vol. 930, pp. 79-93, July 2002.

[7] Q. Lan, A. S. Bassi, J. Zhu, and A. Margaritis, "A modified Langmuir model for the prediction of the effects of ionic strength on the equilibrium characteristics of protein adsorption onto ion exchange/affinity adsorbents," Chemical Engineering Journal, vol. 81, pp. 179-186, January 2001

[8] H. F. Xia, D. Q. Lin, and S. J. Yao, "Evaluation of new high-density ion exchange adsorbents for expanded bed adsorption chromatography," Journal of Chromatography A, vol. 1145, pp. 58-66, 2007.

[9] R. K. Lewus amd G. Carta, "Protein diffusion in charged polyacrylamide gels visualization and analysis," Journal of Chromatography A, vol. 865, pp. 155, 1999.

[10] W. Kopaciewicz, M. A. Rounds, J. Fausnaugh, and F. E. Regnier, "Retention model for high-performance ion-exchange chromatography," Journal of Chromatography, vol. 266, pp. 3-21, 1983.

[11] X. Jin, J. Talbot, and N. H. L. Wang, "Analysis of steric hindrance effects on adsorption kinetics and equilibria," AIChE Journal, vol. 40, pp. 1685-1696, 1994.

[12] C. M. Roth, K. K. Unger, and A. M. Lenhoff, "Mechanistic model of retention in protein ion-exchange chromatography," Journal of Chromatography A, vol. 726, pp. 45-56, 1996.

[13] J. C. Bosma and J. A. Wesselingh, "pH dependence of ion exchange equilibrium of proteins," AIChE Journal, vol. 44, pp. 2399A, 1998.

[14] W. Fritz and E. U. Schlunder, "Simultaneous adsorption equilibria of organic solutes in dilute aqueous solutions on activated carbon," Chemical Engineering Science, vol. 29, pp. 1279-1282, 1974.

[15] S. G. Hu, D. D. Do, and M. M. Hossain, "Step elution in preparative liquid chromatography," Journal of Chromatography, vol. 605, pp. 175-191, 1992.

[16] I. Langmuir, "The constitution and fundamental properties of solids and liquids," Journal of the American Chemical Society, vol. 38, pp. 2221-2295, 1916.

[17] P. Kumar, P. W. Lau, S. Kale, S. Johnson, V. Pareek, R .Utikar, and A Lali, "Kafirin adsorption on ion-exchange resins: Isotherm and kinetic studies," Journal of Chromatography A, vol. 1356, pp. 105-116, August 2014.

[18] G. L. Skidmore, B. J. Horstmann, and H. A. Chase, "Modeling single component protein adsorption to the cation exchanger S Sepharose FF," Journal of Chromtography, vol. 113, p. 498, 1990.

[19] R. D. Whitley, R. Wachter, F. Liu, and N. H. L. Wang, "Ion exchange equilibria of lysozyme, myoglobin, and bovine serum albumin: effective valence and exchanger," Journal of Chromatography, vol. 465, pp. 137-156, 1989.

[20] H. Yoshida, M. Yoshikawa, and T. Kataoka, "Parallel transport of bsa by surface and pore diffusion in strongly basic chitosan," AIChE Journal, vol.40, no. 12, pp. 2034-2044, December 1994.

[21] A. Tonga, A. I. Liapis, and D. J. Sieher, "Equilibrium and kinetic parameters of the adsorption of $\alpha$-Chymotrypsinogen A onto hydrophobic porous adsorbent particles," Journal of Chromatography $A$, vol. 21, p. 686, 1994.

[22] K. Miyabe and G. Guiochon, "Kinetic study of the concentration dependence of the mass transfer rate coefficient in anion-exchange chromatography of bovine serum albumin," Biotechnology Program, vol. 15 , pp. 740-752, 1999.

[23] L. E. Weaver and G. Carta, "Protein adsorption on cation exchangers: comparison of macroporous and gel composite media," Biotechnology Program, vol. 12, pp. 342-355, 1996.

[24] G. M. S. Finette, Q. M. Mao, and M. T. W. Hearn, "Comparative studies on the isothermal characteristics of proteins adsorbed under batch equilibrium conditions to ion-exchange, immobilised metal ion affinity and dye affinity matrices with different ionic strength and temperature conditions, " Journal of Chromatography A, vol. 763, pp 71-90, 1997

[25] P. R. Wright, F. J. Muzzio, and B. J. Glasser, "Batch uptake of lysozyme: Effect of solution viscosity and masstransfer on adsorption," Biotechnology Progress, vol. 14, pp. 913-921, October 1998.

[26] H. Pedersen, L. Furler, K. Venkatasubramanian, J. Prenosil, and E. Stuker, "Enzyme adsorption in porous supports: local thermodynamic equilibrium model," Biotechnology and Bioengineering, vol. 26, pp. 961-971, 1985.

[27] R. D. Tilton, C. R. Robertson, and A. P. Gast, "Lateral diffusion of bovine serum albumin adsorbed at the solid-liquid interface," Journal of Colloid and Interface Science, vol. 137, no. 1, pp. 192-203, 1990.

[28] H. Yoshida, M. Maekawa, and M. Nango, "Parallel transport by surface and pore diffusion in a porous membrane," Chemical Engineering Science, vol. 46, p. 429, 1991. 
[29] Z. Ma, R. D. Whitley, and N. H. L. Wang, "Pore and surface diffusion in multi-component adsorption and liquid chromatography systems," AIChE Journal, vol. 42, p. 1244, 1996.

[30] F. Helfferich, Ion Exchange, McGraw Hill Book Company Inc., Newyork, 1962, p. 150.

[31] F. Helfferich and M. S. Plesset, "Ion exchange kinetics - A nonlinear diffusion problem," Journal of Chemical Physics, vol. 28. pp. 418-424, 1958.

[32] E. Boschetti, "Advanced sorbents for preparative protein separation purposes," Journal of Chromatography A, vol. 658, pp. 207-236, 1994.

[33] N. Unlü and M. Ersoz, "Adsorption characteristics of heavy metal ions onto a low cost biopolymeric sorbent from aqueous solutions," Journal of Hazardous Materials, vol. 136, pp. 272-280, August 2006.

[34] Y. D. Huang, J. X. Bi, and Z. G. Su, Protein Expression and Purification, vol. 74, pp. 257-263, 2010.

[35] S. Andreas, S. Bommarius, and M. F. Paye, "Stabilizing biocatalysts," Chemical Society Reviews, vol. 15, 2013

[36] A. Velayudhan, "Studies in nonlinear chromatography," Doctoral dissertation, Yale University, 1990.

[37] D. D. Frey, E. Schweinheim, and C. Horva'th, "Effect of intraparticle convection on the chromatography of biomacromolecules," Biotechnology Progress, vol. 9, pp. 273-284, 1993.

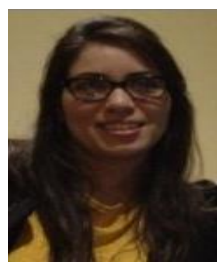

Manel Wakkel was born in Nabeul, Tunisia on January 1, 1985. She received her engineering diploma in bio-industry in 2009 and her master degree in industrial biotechnology in 2011 from the national institute of applied sciences and technology, INSAT-Tunisia. Actually, she is a $\mathrm{PhD}$ student in chemical and environmental engineering - LISBP INSA Toulouse France. Her current research interests focus on the separation of proteins from complex media by ion exchange chromatography and the comprehension of the mechanisms involved in this chromatographic process.

Sandrine Alfenore was born in Toulouse, France in 1974. She received her technician diploma in physical measurements speciality in 1993, her master degree in physico-chemical processes in 1995 and her research master degree in process engineering in 1996. She received her PhD diploma in process engineering with a speciality in industrial microbiology in 1999. Actually, she is an assistant professor at INSA Toulouse France. Her research interests focus on microbial engineering, yeasts physiology and activity, bioprocesses

Stéphane Mathé was born in Angouleme, France in 1967. He received his $\mathrm{PhD}$ diploma in organic and bio-organic chemistry in 1997. Currently, he is an assistant professor in chemistry at LISBP, INSA Toulouse France. His research interests focus on analytic chemistry, Ion-exchange and chromatographic processes, valorisation of effluents.

Aurora Fernández was born in Mieres, Spain, on December 17, 1964 Actually, she is a professor in chemical engineering (LISBP) and director of chemical and environmental engineering department (INSA - Toulouse, France). Her research interests focus on mass transfer, ion-exchange and chromatographic processes, valorisation of effluents. 